\title{
DECIFRA-ME OU DEVORO-TE
}

\author{
Joāo (Alegria) Alves dos Reis Junior*
}

\begin{abstract}
RESUMO: A popularização do hardware e do software para produção de textos, sons e imagens, torna mais viáveis os planos daqueles que se propōem a produzir mídia com crianças e adolescentes num contexto educativo. Muitos são os que buscam uma leitura lúcida e crítica da programação da TV, dos websites e mesmo da imprensa escrita a partir da experimentação empírica da produção de audiovisuais. Pois, para boa parte dos teóricos e educadores, os males da mídia residiriam basicamente no conteúdo que ela veicula e na padronização dos formatos e da linguagem audiovisual dos produtos, problemas que poderiam ser superados com uma reflexão a partir de uma produção alternativa. Este artigo sistematiza alguns aspectos da evolução da TV e da audiência nos últimos anos e aponta a tendência de produção de mídia com crianças e adolescentes que vem sendo colocada em prática nas escolas e organizaçôes não-governamentais, como parte essencial do processo de formação dos futuros cidadãos.
\end{abstract}

Palavras-chave: Mídia. Educação. Crianças e adolescentes.

\section{EITHER FIGURE ME OUT OR I'LL EAT YOU ALIVE}

ABSTRACT: The popularization of the hardware and the software in the production of texts, sounds and images makes more practical the plans of those who propose themselves to produce media with children and adolescents in an educational context. Many are those who look for clear reading and critic of the TV programming, of the web sites and even the printed press, based on empirical experiments of the audio visual production. Thus, for many theoreticians and educators the evils from the media would reside basically in the contents it vehiculates and in the stardardization of formats and of the audio visual language of the products, which can be overcome with a reflection as of an alternative production. This article classifies

Autor e diretor de TV, doutorando do Programa de Pós-Graduação em Educação Brasileira da Pontifícia Universidade Católica do Rio de Janeiro (PUC-RIO). E-mail: alegria@alternex.com.br 
some aspects of the TV audience and evolution in the last years and points out the media production trend with children and adolescents that has been put into practice in schools and non-governmental organizations as essential part of the education process of the future citizens.

Key words: Media. Education. Children and adolescents.

\section{Passividade, escolha e produção própria de mensagens}

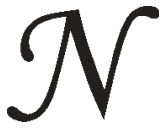

os últimos anos temos assistido à irrupção de uma controvertida discussão sobre a influência dos produtos de comunicação de massa na formação das crianças e dos adolescentes. As preocupações externadas por vários setores da sociedade são legítimas, principalmente tendo-se em vista a alegada falta de qualidade de conteúdo e inadequação de linguagem dos produtos da mídia destinada aos públicos dessas faixas etárias. No pivô desta discussão se encontra a televisão, o veículo de comunicação de massa mais difundido no Brasil. Como diz Nelson Hoineff (2003, p. 8):

Qualidade em televisão depende em grande medida da adequação formal e narrativa do conteúdo ao meio. (...) O que a televisão gera hoje é em grande parte não apenas ofensivo ao cidadão como inibidor de seu crescimento. A maior parte dos brasileiros se forma através da televisão e o tipo de formação que ela vem produzindo é indiscutivelmente nefasto.

Na opinião de Hoineff, como na de boa parte dos críticos, o problema não estaria tanto na natureza do veículo, mas na "adequação formal e narrativa do conteúdo ao meio". Ou seja: no "que a televisão gera". Pois, como tecnologia da comunicação, a televisão oferece recursos fundamentais à sociabilidade contemporânea (Martín-Barbero, 2002). A TV é mágica e - ao mesmo tempo - inegavelmente realista. É verdadeira e fabulosa: como na razão infanto-juvenil, a TV justapóe realidade e ficção num complexo emaranhado de conteúdos verbais e impulsos visuais que só os iniciados conseguem distinguir com perfeição.

A TV é interativa e dispõe de controles que, quando acionados, trazem conseqüências surpreendentes e deliciosas. Ela possui cores fortes e luminosidade própria, associa imagem e som, é uma ponte de acesso virtual para tudo o que existe e até para o que não existe. Além 
disso, a TV está em todos os lugares: nos lares, no trabalho, nas ruas. É onipresente.

Durante grande parte de sua existência a televisão foi um meio de comunicação autoritário, na medida em que pressupunha e exigia um público passivo, imobilizado na sala de estar diante da telinha. $\mathrm{O}$ discurso emitido pelo aparelho preponderava e o recorte do real exibido em sua tela consistia na verdade absoluta sobre os fatos. Essa situação persistiu até o final dos anos de 1970. Nos anos de 1980, a multiplicação do número de emissoras e programas e a disseminação do videocassete doméstico e do controle remoto transformaram a situação anterior. $\mathrm{O}$ espectador adquiriu maior controle sobre a sua programação pessoal ao dispor da possibilidade de escolher o quê gostaria de ver e quando.

Já na década de 1990, com a evolução muito rápida dos equipamentos eletrônicos e sua popularização, principalmente após a difusão da rede mundial de computadores, a tônica passou da escolha da programação para a inesperada e surpreendente possibilidade de produção de uma programação própria. Nunca foi tão fácil e barato gravar imagens, editar essas imagens na forma de uma mensagem, associando a ela sons e informaçōes gráficas. Nunca foi tão fácil gravar um disco, criar e difundir para milhares de pessoas ao mesmo tempo mensagens textuais, visuais e sonoras. ${ }^{1}$

Tais transformações impuseram às emissoras de TV a necessidade de gerar programação interativa, estabelecendo um novo modo de interação na comunicação de massa, em que o receptor opina nas decisões sobre qual mensagem será emitida, quando e como ela o será. Essa interatividade ocorre de vários modos: A) Escolha do que se vai ver amanhã, semana que vem; de qual final mais agrada; de que rumos uma programação deve tomar para satisfazer a audiência. B) Participação a distância: por meio de telefone, jogos interativos, webcams, internet. C) participação presencial: convidados aos programas de games; aos programas de entrevistas, auditório, talk shows.

De modo genérico, interatividade na TV significa uma programação que se aproxima dos interesses da audiência. Não exige sua participação direta, mas pressupõe uma audiência atenta aos rumos e ao formato da programação. Assim, conseqüentemente, teríamos uma TV contemporânea transformada num veículo de comunicação de massa menos autoritário e excludente, moldado, em parte, pela vontade e 
pelo interesse do espectador. ${ }^{2}$ Como então explicar que, mesmo assim, persistam tantas críticas à falta de qualidade de conteúdo e inadequação de linguagem dos produtos da mídia?

\section{Crianças e adolescentes mais bem equipados para a comunicação}

Abraham Moles, na distante década de 1970, afirmou:

A televisão já constitui o meio de comunicação de massa fundamental dentro da Sociedade Tecnológica e é, sobretudo, como tal considerada. O receptor de TV é o objeto que encabeça a lista dos elementos componentes do meio ambiente em nossa sociedade; sua preeminência transformou-o no determinante social fundamental do Umwelt cotidiano, bem mais importante que as formas jurídicas, os objetos mobiliários ou a coisa escrita. (...) Ver televisão é, no inventário das situações, o que se pode chamar de situação forte, uma constante da vida cotidiana. (Moles, 1973, p. 70)

Por ter a televisão uma presença "forte" no cotidiano, como aponta Moles, atribui-se à sua programação o poder de influenciar o comportamento em sociedade e uma capacidade ímpar de formação do senso comum. No livro Fala galera podemos vislumbrar o que professores e alunos das escolas públicas e privadas do Rio de Janeiro pensam sobre o assunto:

A maioria dos entrevistados concorda que a televisão faz a cabeça dos jovens quando se trata de moda, a "ditadura da estética" e o incentivo ao consumo do supérfluo. "A televisão veste os jovens, $70 \%$ dos jovens vestem o que a mídia diz" (alunos das escolas particulares). "Todo comercial é influenciativo, por mais que você não queira, você fica sempre lembrando, vê aquele objeto, passa na rua e vê aquele refrigerante, aí você lembra do comercial que diz que é gostoso" (alunos das escolas públicas). Na sua listagem de evidências da ligação do consumo com a propaganda, os rapazes e moças lembram a "gillete" para fazer a barba; a caneta "Bic" que você usa; a fotocópia "xerox" que você faz. (...) E articulam esse fato com a opção de muitos jovens pobres pela entrada no mundo do tráfico de drogas para comprarem aquilo a que não teriam acesso pelos meios legais. (Minayo, 1999, p. 144)

Realmente, salvo exceções, os horários de programação infantil e juvenil estiveram durante décadas destinados ao entretenimento inconseqüente e irresponsável e ao incremento do comércio de subprodutos. 
Caracterizando uma programação estruturada em conseqüência do mercado, o que ainda é regra nos dias de hoje.

Acredita-se que tal utilização do tempo de mídia venha colaborando de forma direta para a conformação da sociedade contemporânea e de alguns de seus dilemas. A violência urbana, a intolerância religiosa e cultural, o consumismo, o individualismo exacerbado e a falta de respeito ao próximo e ao meio ambiente em que vivemos seriam marcas da idade mídia, que caracteriza "a opção de muitos jovens pobres pela entrada no mundo do tráfico de drogas para comprarem aquilo a que não teriam acesso pelos meios legais", como indicam os adolescentes e professores entrevistados no Rio de Janeiro.

No tempo presente a televisão, a internet e os jogos eletrônicos ocupam o espaço complementar à escola e à família na educação. Quando não um espaço significativo dentro da própria escola. Muitos adolescentes e crianças brasileiros passam mais tempo em frente da TV que na sala de aula - é na TV e em outras mídias que buscam suprir sua necessidade de novos conhecimentos e estímulos. No Brasil, a televisão preenche as lacunas geradas pela falta de acesso a teatro, cinema, lazer e informação. Em muitos casos a TV parece querer substituir a escola com produções de ensino a distância e disseminadas em telessalas e telecursos, onde se pretende uma recepção orientada da estética e do conteúdo.

A novidade é que os vários estímulos oriundos de videogames, computadores, internet e programas de TV funcionam como uma ginástica para o cérebro. As novas tecnologias disponíveis, a velocidade e a variedade da informação dão às crianças e aos adolescentes mais recursos para a comunicação (Lévy, 1993).

A isso se pode somar a herança da cultura visual e televisiva do século $\mathrm{XX}$, o que faz com que os garotos já nasçam sabendo ver TV, ou consumir mídia, como se fosse possível seu organismo estar previamente equipado com noções de montagem cinematográfica. Como se a existência na idade mídia estabelecesse para as novas geraçóes exigências de um padrão de comunicação que coloca em xeque os métodos tradicionais de aprendizagem e organização social. Inaugura-se uma nova moral, uma nova estética, enfim, uma nova ordem.

Se por um lado nos deparamos com esses seres mais bem equipados para entender e se relacionar com os mecanismos da informação contemporânea, no sentido de decodificar suas mensagens, por outro, 
por vezes, é a ingenuidade do indivíduo perante o veículo de comunicação, os artifícios de linguagem e a natureza da mensagem o que chama a atenção.

Nisto se afirma boa parte das propostas de uma educação para a comunicação. Acredita-se que, sem dominar os processos de construção de mensagens, dificilmente o jovem espectador poderá analisar criticamente os produtos à sua disposição ou ser menos influenciado por eles.

Como afirma o professor Roger Silverstone em entrevista à revista Carta Capital:

A cidadania no século XXI requer um grau de conhecimento que até agora poucos de nós têm. Que requer do indivíduo que saiba ler os produtos de mídia e que seja capaz de questionar suas estratégias. Isso envolveria capacidades que vão além do que foi considerado alfabetização em massa na época da mídia impressa. (...) Eu sugiro que a alfabetização em mídia é mais necessária do que nunca, precisamente porque ela é fundamental para a construção de identidades, o senso de nós mesmos no mundo e nossa capacidade de agir dentro dele. (Silverstone, 2003, p. 58)

Aproveitando-se da disponibilidade de softwares e hardwares, hoje mais acessíveis, criando atividades educativas que se valem de produtos da mídia, ou então projetos pedagógicos com o objetivo de produzir mídia. Considerando professores, alunos, agentes sociais e cidadãos como produtores de mensagens - e não apenas simples receptores -, e o ambiente de formação como um dos lugares da produção de mídia de qualidade, surge o que poderíamos definir por uma forte tendência à produção de mídia com crianças e adolescentes como parte essencial do seu processo de formação. ${ }^{4}$

\section{Decifra-me ou devoro-te}

A televisão evoluiu no sentido de absorver a participação popular sem se distanciar dos interesses de mercado que orientam sua programação. A audiência, atendendo aos novos padrões de sociabilidade, demonstra uma grande capacidade de absorção das novas tecnologias, afirmando-se como consumidora voraz de todo gênero de mídia. Será que as iniciativas de produção de mídia com crianças e adolescentes têm cumprido a tarefa a que se propóem? 
Em grande medida, esses projetos concentram esforços na capacitação de crianças e adolescentes, para que se comuniquem com o auxílio das ferramentas de produção de mídia. Têm se dedicado a ensinar a usar a câmera como os cameramen, a redigir como roteiristas e a produzir audiovisuais como produtores profissionais. Muitas vezes, poder-se-ia afirmar que a mera realização de audiovisuais acaba tomando o lugar da proposta inicial: uma reflexão crítica a partir do conhecimento e domínio do processo de produção de TV, do rádio, da internet e da mídia impressa.

Cecília von Feilitzen, a partir de dezenas de experiências de produção de mídia com crianças e adolescentes em todo o mundo, resume:

(...) a educação para a mídia não pode, de acordo com os direitos da criança, basicamente objetivar apenas proteger as crianças de certos conteúdos da mídia, injetando nelas certos princípios e opinióes que lhes ensinem a dissociar-se do mau conteúdo da mídia e selecionar o de boa qualidade. Tampouco deveria a educação para a mídia objetivar ensinar as crianças a desconstruir as mensagens e ver através do poder, isto é, compreender nos interesses de quem e com quais objetivos as mensagens são transmitidas. A educação para a mídia também deve envolver uma tentativa para mudar a produção da mídia e a situação na sociedade, por meio da própria produção e participação da criança, entre outras coisas. $\mathrm{O}$ direito à mídia e à informação, o direito à liberdade de expressão e o direito de um indivíduo expressar suas opiniōes sobre aquilo em que as questôes o afetam devem, na sociedade de hoje, também significar participação na mídia. (Feilitzen, 2002, p. 27)

No entanto, lendo muitos dos relatos reunidos por Feilitzen, ouvindo comunicações em congressos, escarafunchando os sites de organizações não-governamentais na internet, o que se pode entrever é um grande esforço de apropriação da tecnologia, em detrimento da criatividade e do pensamento crítico, que poderiam, estes sim, trazer os bons ventos da renovação dos formatos e da qualidade do conteúdo.

O que preocupa é a importação dos métodos desenvolvidos em decorrência do mercado, em detrimento da invenção de novas soluções de produção. É o privilégio do discurso já estabelecido, submetendo o olhar diferenciado das crianças e dos adolescentes a uma visão crítica préformatada pelos adultos.

Foi possível verificar empiricamente algumas destas assertivas durante a realização do projeto intitulado "Oficina TVE de Mídia", quando, entre 2 de setembro e 14 de dezembro de 2003, um grupo 
de crianças e adolescentes participou de encontros semanais nas dependências da TVE, no Rio de Janeiro, com o objetivo de produzir um vídeo para exibição no Dia Internacional da Criança no Rádio e na TV.

Partindo do princípio de que a criação e a "contação" de histórias estão na base de toda forma de mídia, o trabalho esteve centrado no exercício da criatividade e na valorização das narrativas pessoais e coletivas. Estes foram os principais norteadores na preparação e na realização das atividades semanais com o grupo de participantes das oficinas.

Este enfoque facilitou o resgate e o reconhecimento da identidade do grupo e de cada um dos meninos e das meninas envolvidos no processo. A expressão das identidades particulares e o estabelecimento de uma identidade coletiva são partes essenciais desse trabalho. Permitem configurar um território criativo palpável e com o qual os participantes se identificam.

Como a compreensão do conceito de identidade é ampla, é preciso esclarecer que, nesse caso, sua utilização refere-se principalmente aos aspectos concernentes à história audiovisual dos participantes, que advém da cultura audiovisual vigente e da maneira, diferenciada em cada contexto, como se dá a recepção dos produtos veiculados pelas diferentes mídias.

Mesmo tendo se realizado nas dependências de uma emissora de $\mathrm{TV}$, o projeto incluiu a tecnologia como um meio e não como um fim. Seria compreensível que os profissionais envolvidos no processo buscassem apenas transmitir sua habilidade e conhecimento técnico. Porém, câmeras, ilha de edição e computadores estiveram a serviço das histórias que foram criadas com a mínima interferência possível dos adultos. Antes, as crianças e os adolescentes foram estimulados a criar uma mensagem. O domínio da tecnologia tornou-se importante à medida que se pretendia dar corpo e forma a um determinado conteúdo e não há como negar: a qualidade dos produtos realizados durante o projeto deve-se, em muito, à liberdade de criação que antecedeu os limites técnicos impostos pelas características dos equipamentos empregados durante a realização dos produtos.

Em muitas iniciativas de produção de mídia com crianças e adolescentes fica evidente o privilégio à razão em detrimento do corpo e dos sentidos como mediadores na apreensão do real. Quando as atividades se restringem a discussões e aulas teóricas, é mais fácil cair na armadilha da 
reprodução do discurso corrente que versa sobre a qualidade, ou a falta dela, nos meios de comunicação. Não raro a propalada conscientização crítica se limita à reprodução de fórmulas do pensamento difundidas pelos próprios veículos de comunicação de massa. Durante a realização do projeto, o lugar do corpo e dos sentidos na apreensão do real foi recuperado por intermédio de atividades oriundas do repertório da arte-educação.

Uma solução semelhante foi adotada com sucesso durante a produção do programa de TV Abrindo o verbo, realizado com alunos adolescentes das escolas públicas municipais do Rio de Janeiro. ${ }^{6}$ Inicialmente a reprodução dos diferentes discursos sociais sobre o sexo na adolescência, o uso de drogas ou os conflitos familiares, entre outros, impedia a expressão genuína das emoções e de reflexões dos próprios entrevistados. À medida que as gravações abriram espaço para dinâmicas corporais, jogos e representaçôes, foi possível aprimorar a escuta da opinião dos jovens.

Outra questão relevante é o estabelecimento de uma relação clara de confiança e compromisso mútuo, entre participantes, orientadores das atividades educativas e instituição. Por vezes há um zelo excessivo dos orientadores quando se trata do manuseio de equipamentos de produção por crianças e adolescentes. O que é justificado em razão do custo alto dos aparelhos e resulta na quebra de laços vitais entre todas as partes envolvidas no processo. A falta de confiança também pode manifestar-se na dúvida relativa à capacidade de realização das crianças e dos adolescentes, o que é ainda mais grave.

Crianças e adolescentes estão aptos a realizarem e a se expressarem por intermédio da mídia. Inclusive, geralmente se mostram ansiosos em fazê-lo. Assim, é aconselhável tornar os encontros produtivos, permitindo que os participantes coloquem a mão na massa, realizando, se possível, pequenos produtos a cada oficina.

Por fim, merece destaque a importância do envolvimento dos familiares e responsáveis, que devem estar cientes das atividades desenvolvidas com as crianças e os adolescentes e de seus objetivos. Quiçá possam participar de algumas delas, ou de outras, desenvolvidas especialmente para eles com os mesmos fins daquelas que foram propostas aos seus filhos.

Certamente essas observações não esgotam o aprendizado que a "Oficina TVE de Mídia” pode propiciar. Um relato completo envolvendo as reflexões dos demais participantes do processo está em andamento e será divulgado oportunamente. $\mathrm{O}$ objetivo destes primeiros aponta- 
mentos é apoiar a afirmação da necessidade de revisão das metodologias que vêm sendo empregadas na produção de mídia com crianças e adolescentes.

\author{
Restam muitos enigmas por decifrar. É como se, ao olhar para a \\ esfinge da comunicação, mais uma vez no horizonte, ainda se pudesse \\ ouvir o eco da ameaça milenar: decifra-me ou devoro-te.
}

\title{
Recebido em fevereiro de 2005 e aprovado em março de 2005.
}

\section{Notas}

1. Muitos brasileiros não têm condições de possuir um computador pessoal. No entanto, a quantidade de equipamentos eletroeletrônicos e até de computadores adquiridos recentemente no Brasil é significativa. Atualmente os microcomputadores podem ser comprados em lojas de departamentos e supermercados, com o pagamento facilitado por financiamento direto ao consumidor e crediário. O computador entrou na lista dos objetos do desejo dos brasileiros, ao lado do automóvel e da casa própria. À sua posse comumente se associa a possibilidade de mudança de condição de vida, para melhor. Os cidadãos de diferentes segmentos sociais, em contrapartida, mesmo que não possuam computador pessoal, vêem-se obrigados a lidar com a informática no dia-a-dia das compras e na administração pessoal dos próprios recursos, em razão da informatização dos bancos e dos sistemas de pagamentos de salário e acesso à saúde, por exemplo. Isto é, todos são obrigados a viver numa sociedade cada vez mais informatizada.

2. Certamente, é preciso ressaltar que o acesso a determinados gêneros de informação está diretamente relacionado às condições socioeconômicas. Como ilustram os resultados da pesquisa "A voz dos adolescentes", realizada no ano de 2002 pelo UNICEF Brasil com mais de 5 mil adolescentes de todo o território nacional. Quanto ao acesso à informação: com relação a fontes de informação, $59 \%$ dos entrevistados afirmam ler jornais e revistas "às vezes". Na classe A, 27\% dizem ler "sempre" e 9\% não lêem "nunca". Os números invertem-se à medida que o nível de renda decresce. Na classe B, 20\% lêem sempre e $18 \%$ nunca lêem. Na classe C, $14 \%$ lêem sempre e $26 \%$ nunca lêem e, na classe D, $9 \%$ lêem sempre e $32 \%$ nunca lêem jornais e revistas. Entre os adolescentes entrevistados na pesquisa, $27 \%$ têm acesso à internet. Se avaliarmos o acesso à rede mundial de computadores segundo as classes sociais, verificamos que, ao passo que na classe A $72,4 \%$ dos entrevistados utilizam a internet, o mesmo ocorre com 52,3\% dos adolescentes na classe B, $20,8 \%$ na classe $\mathrm{C}$ e $12,9 \%$ na classe D. $33,7 \%$ dos adolescentes brancos têm acesso à internet e $21,9 \%$ dos pretos. Pardos (22,8\%), amarelos (26\%) e indígenas (16,2\%) (informações constantes das tabelas 109 e 111). Mas ter pouco acesso a jornais e internet, por exemplo, não significa estar fora da influência da mídia. Se forem poucos os que lêem jornal habitualmente, quase a totalidade da população está ligada à televisão e tem nela sua principal fonte de informaçôes. Também é preciso considerar que, no caso do Brasil, a exclusão dos meios de produção de mensagens tem sido relativizada pelas incontáveis iniciativas de produção de mídia coordenadas pelas organizações não-governamentais e pelas escolas públicas. As ONGs têm desempenhado um importante papel na democratização dos meios de produção de mensagem em todo o mundo. Uma visão dessas iniciativas pode ser obtida na página do UNICEF, disponível em: <www.unicef.org/magic>. 
3. A idéia de alfabetizar para a mídia é bastante corrente em meio às discussões acerca da educação para a mídia. A expressão é herdeira do paralelo com a suposta necessidade de domínio da leitura e da escrita posterior ao advento da prensa e da difusão do texto impresso. Seria interessante verificar o verdadeiro impacto que este fato histórico teria provocado na sociedade da época antes de fazermos valer a comparação. Neste sentido, é possível destacar, por exemplo, o estudo de Natalie Zemon Davis (1990): Culturas do povo, que merece ser consultado.

4. A aproximação entre escola e mídia, na verdade, deixou de estar restrita ao discurso de críticos e educadores e passou a constar do texto de vários documentos legislativos ou normatizadores da educação em âmbito federal, estadual e municipal. A importância das várias linguagens faz-se presente na Lei de Diretrizes e Bases da Educação Nacional, nos Parâmetros Curriculares Nacionais e em documentos como o Núcleo Curricular Básico Multieducação da Secretaria Municipal de Educação do Rio de Janeiro, em que se pode ler: "Compreender o papel das linguagens como instrumento de mediação transformadora no diálogo do homem consigo próprio, com o outro e com o mundo e que estas linguagens transformadoras podem ser dirigidas à compreensão entre grupos sociais, cidades, estados e países em busca de Paz e da convivência digna e construtiva". Observe-se que, por "linguagens", o texto em questão quer referir-se aos avanços e recursos tecnológicos e à comunicação de massa, aproximando a comunidade escolar das conquistas da sociedade contemporânea no campo da comunicação. De algum modo podemos detectar o advento de uma escola produtora de mídia.

5. A "Oficina TVE de Mídia” é um projeto da Assessoria de Educação (atual Núcleo de Criação 4) da TVE Rio. No ano de 2003 ocorreu entre os dias 2 de setembro e 14 de dezembro, reunindo semanalmente um grupo de crianças e adolescentes oriundos de escolas públicas e sem experiência anterior na criação e realização de audiovisuais. Os encontros foram coordenados por Camila Leite e João Alegria e tiveram como objetivo final a produção de um vídeo para exibição no Dia Internacional da Criança no Rádio e na TV, um evento internacional anual coordenado pelo Unicef. Algumas das observações apresentadas a seguir refletem as discussões de avaliação realizadas pela equipe responsável pelo projeto. Mais detalhes podem ser obtidos no portal da TVE, disponível em: <www.tvebrasil.com.br/oficinatvedemidia>.

6. O programa Abrindo o verbo é uma realização da Multirio, Empresa Municipal de Multimeios vinculada à Secretaria Municipal de Educação do Rio de Janeiro. Trata-se de um programa semanal com 30 minutos de duração, no qual adolescentes oriundos das escolas públicas conversam sobre as questôes que mais os afligem.

\section{Referências bibliográficas}

\section{DAVIS, N.Z. Culturas do povo: sociedade e cultura no início da França moderna. Trad. de Mariza Corrêa. São Paulo: Paz \& Terra, 1990.}

FEILITZEN, C. V. Educação para a mídia, participação infantil e democracia. In: Carlsson, U.; Feilitzen, C.V. (Org.). A criança e a mídia: imagem, educação, participação. São Paulo: Cortez; Brasília, DF: UNESCO, 2002. 
HOINEFF, N. A nova televisão: desmassificação e o impasse das grandes redes. Rio de Janeiro: Relume-Dumará, 1996.

HOINEFF, N. Entrevista. Nós da Escola, Rio de Janeiro, n. 11, p. 6-9, mar. 2003. (Mídia e educação em debate)

LÉVY, P. As tecnologias da inteligência: o futuro do pensamento na era da informática. Rio de Janeiro: Editora 34, 1993.

MARTÍN-BARBERO, J. La educación desde la comunicación. Buenos Aires: Norma, 2002.

MINAYO, M.C.S. Dentro e fora do espetáculo: a mídia. In: MinaYo, M.C.S. et al. Fala galera: juventude, violência e cidadania na cidade do Rio de Janeiro. Rio de Janeiro: Garamond, 1999.

MOLES, A. Rumos de uma cultura tecnológica. São Paulo: Perspectiva, 1973.

SILVERSTONE, R. Por que estudar a mídia? São Paulo: Loyola, 2002. SILVERSTONE, R. Entrevista. Carta Capital, São Paulo, p. 58, 12 fev. 2003. 